\title{
The potentials of and barriers to the utilization of advanced computer systems in remote construction projects: case of the Kingdom of Saudi Arabia
}

\author{
Bhzad Sidawi ${ }^{*}$ and Abdulsalam Alsudairi
}

\begin{abstract}
Background: An extensive body of knowledge indicated the positive impact of the Advanced Computer based Management Systems (ACMS) on various aspects of project management, while highlighting barriers that hinder adoption, diffusion, and utilization of the ACMS by the construction industries around the world. Remote projects have their unique management problems and these are caused mainly by the remoteness of the project. Little research was undertaken concerning this issue, particularly in the Persian Gulf region, and it has highlighted few unique communications and management problems such as the loose control, lack of human resources, infrastructure and experience.

Methods: This research investigated the use of ACMS by large companies in the Eastern province, Kingdom of Saudi Arabia (KSA), and how it would help these companies sorting out a number of present projects' management problems. Subsequently, a field study i.e. a questionnaire survey and interviews was carried out.

Result: The field study revealed significant association between frequent management problems with little use of ACMS and the domination of use of traditional communications and management systems. This paper argues that the use of traditional systems and the traditional way of sorting out construction problems limit the applicability of ACMS.

Conclusion: The present researchers recommend the use of customized ACMS associated with the application of lean and sustainable management principals as these would help overcoming barriers and providing intelligent solution for the strategic, technical, and social issues of the remote construction sites.
\end{abstract}

Keywords: Mobile systems; Web-based project management systems; Remote construction projects

\section{Background}

Remote construction projects exist in many regions throughout the world such as the Sahara desert, Antarctic regions, the Arabian Peninsula desert, the Australian desert, the Empty Quarter etc. The dilemma in managing remote projects is highlighted by Deng et al. (2001), Kestle and London (2002, 2003), Kestle (2009), McAnulty and Baroudi (2010), and Thorpe (2000). These authors have pointed out that the remoteness thus the loose control is major cause of the management problems. They suggested possible causes such as the lack of human resources,

\footnotetext{
* Correspondence: Bsidawi@ud.edu.sa

Architecture Department, College of Architecture and Planning, University of Dammam, 31451 Dammam, P O Box 2397, Kingdom of Saudi Arabia
}

infrastructure and experience of how to manage these remote projects. In the Kingdom of Saudi Arabia, remote construction sites have unique problems and these have been highlighted by Justanyah and Sidawi (2011), Sidawi 2010a,b, 2012a,b.

The literature review suggested that some of the project management and communications problems are caused by the use of inappropriate tools and systems for communication, coordination, and management. For example, Yang et al. (2007) suggested that intense need for project information and effective communications by the project team cannot be met by traditional communications and information management systems since these systems have shortcomings and are incapable of fulfilling project 
duties and objectives. One of these shortcomings is that traditional systems provide limited access to information, which is considered one of the key barriers to successful project management practices (Vadhavkar and Pena-Mora 2002; Pena-mora et al. 2009). Many of these project failures are caused by inadequate organization and management of the construction process (e.g., a weak coordination of processes and uncertainty about available information) (Wamelink et al. 2002).

These management problems can be sorted out by the use of ACMS such as mobile, Web-based Project Management Systems (WPMS), augmented reality and BIM (Alshawi and Ingirige 2003 and Stewart and Mohamed 2004, Nitithamyong and Skibniewski 2004, 2006, Charoenngam et al. 2004, Arayici and Aouad 2010, Arayici et al. 2012). These systems use wireless, satellite, Internet-based, or mobile tools and networks and it helps - to a certain degree - construction industry firms manage the increasing complexity of normal construction projects. They have also helped fulfill project objectives such as quality, scope, time, and cost. Sustainable practices and measures would also help in sustaining the quality of projects, eliminate waste, and minimize the cost (Arayici et al. 2012). Previous research however, highlighted the barriers that affect the adoption, diffusion, and full application of the technology (Alshawi and Ingirige 2003, Nuria 2005; Leskinen 2006, 2008, Nitithamyong and Skibniewski 2007).

In the KSA, some large companies such as Aramco and Royal commission of Jubail (RCJ) have a number of remote construction projects. These projects are of different sizes i.e. medium, large to very large. They are in remote locations and some operate in undeveloped and environmentally sensitive regions. They are far from the supervision team office, the contractor's office, and major urban concentrations. During construction, all project parties experience countless difficulties and cumbersome management problems. These potential problems negatively affect project quality and cause substantial delays and increases in costs. This paper investigates the potential use of ACMS by large companies in the Eastern province in managing remote projects and barriers that hinder the potential use, and how ACMS would help these companies in sorting out project's problems and improving their management practices.

\section{Literature review}

\section{Remote construction sites problems}

The dilemma of managing remote projects is highlighted by Deng et al. (2001), who mentions that the extensive physical distance between project participants, sometimes extending over national boundaries, is the primary cause of delays in decision making. The project team has to not only tackle traditional management problems but those that specifically occur as a result of the remote locations of these often environmentally sensitive sites (Kestle 2009; Kestle and London 2002, 2003). These sites are often far from logistic support and suffer a continuous shortage of materials and specialized labor (Kestle and London 2002, 2003). Kestle (2009) investigated the management problems of remote projects and reports lack of project pre-planning, certainty, and/or clarity concerning project process integration. There were also misinterpretations and miscommunications of project results and needs issues. A centralized decision-making process and lack of delegated authority to field personnel often hindered progress and communications at critical emergency response and recovery stages. Kestle and London (2002) suggested a framework for the design management of remote sites. The framework emphasizes the following management functions: serving, controlling, organizing and economizing.

McAnulty and Baroudi (2010) conducted a survey of top and mid-tier construction contractors with experience in remote construction projects in Australia. They find that contractors experience difficulty attracting and retaining skilled workers; working in remote locations has a negative impact on an employee's family life. It is difficult to procure and access materials and equipment in remote areas and severe climatic factors in remote areas have a negative impact on productivity. There is lack of infrastructure and communications. The researchers suggest a number of possible solutions such as the need for appropriate material management systems and design cost information specifically for remote construction works. They recommended that unique types of costing issues should be included in the project's cost estimation at the pre-construction stages of project; these include: mobilization/demobilization, accommodation, inclement weather downtime, site allowances, delivery, and productivity.

Justanyah and Sidawi (2011), and Sidawi 2010a,b, 2012a,b examined the case of Saudi Electric Company (SEC). SEC has a number of remote projects and it experiences difficulties in running these projects. These problems can be summarized as the following:

A. Procurement and risk Management: There is a frequent shortage of materials. The delivery of materials and equipment is constrained by $\mathrm{road} /$ highway regulations and bad conditions of some remote roads. Projects have much higher risk margins than ordinary projects. This is caused by the ad hoc approach and both sides i.e. the owner and the contractor do not accurately plan projects.

B. Cost, time, scope, and quality management: There is serious delay in decision-making, loose control, and infrequent visits to the remote site result in wasted 
time, excessive costs, unfocused scope, and poor construction quality.

C. Human Resources: SEC has a staff shortage so employees are incapable of doing all required site visits. There is a lack of security and shortage in skilled workers. The impact of the harsh working conditions has negative impact on the productivity of SEC's supervisors.

D. Infrastructure and communications: Land ownership in some remote areas is not definite or known; legal disputes are likely to occur. There is a lack of or no infrastructure. Contractors and SEC supervisors still use traditional communications and management tools. Decisions are made autocratically and SEC's project managers are not able to control and coordinate integration of a project's aspects and the typical management style is non-standard, fragmented, and loose.

\section{The potentials and barriers to the use of ACMS The potentials of ACMS}

Some of a remote project management's problems can be avoided if ACMS were used. So, it is important to know how far these systems would be capable in sorting remote construction problems. These systems include Web based Project Management Systems WPMS and mobile systems that feature mobile tools, personal digital assistants (PDA), wearable computers, wireless tools, four dimensional augmented reality (4D), virtual reality and other technologies. These systems possess the capability to improve communications between project team members and enable teams to share information and quickly solve problems (Charoenngam et al. 2004). They improve team members' ability to manage time and costs (ibid). Davidson and Moshini (1990) and Bowden (2005) stated that construction costs can be reduced by $25 \%$ through efficient transfer of information between the construction teams; that transfer can be achieved through ACMS. Ahuja et al. (2010) suggested that adoption of Information Communication Technology (ICT) enables effective communication between dispersed project team members but argues that strategic adoption of ICT. This enables them to grasp effectively the IT benefits (Ahuja et al. 2009).

Alshawi and Ingirige (2003) and Stewart and Mohamed (2004) identified the following benefits of using WPMS: productivity enhancement of communication between project participants, reduction in project delays, heightened awareness of project issues among all parties, and ease of access to and retrieval of project information. Other advantages include: avoiding delays due to the arrival of updated drawings and documents, reducing visits to sites and travelling time to meetings, avoiding drawing mistakes, reducing time and money spent on disputes, sharing and exchanging project information, automating repetitive routine processes, and eliminating paper reports. Thomas et al. (2003) discussed how WPMS - from the point of view of selecting contractors helps project managers boost contractor performance and confidence by minimizing subjectivity and eliminating the potential for corrupt practices. This improves competitiveness through increased awareness of competitors' strengths and weaknesses and nurtures mutual trust in the exchange of sensitive information such as performance data. Nitithamyong and Skibniewski $(2004,2006)$ suggested that benefits of using WPMS can be categorized into four main areas. These categories include cost reduction and time saving, enhancement of communications and collaboration, improvement of productivity and partnership, and support of e-commerce and the customer. A number of researchers anticipate that WPMS will replace traditional project management methods (Becerik 2005; Zou and Roslan 2005) and these methods are drivers of WPMS adoption. Several aspects support this claim including increased competitive pressures, expectations of revenue growth, the ability to compete globally, and the desire to reengineer the business to respond to market challenges (Nitithamyong and Skibniewski 2006).

Leskinen $(2006,2008)$ argued that it is difficult to make direct assessment of which mobile systems would benefit the construction industry. The most important intangible benefits include improving customer service, gaining a competitive advantage, acquiring more timely management information, supporting core business functions, avoiding competitive disadvantages, improving management information, improving product quality, improving internal communication, implementing changes through innovation, improving external communication, and enhancing the jobs of employees. In recent years, the development of laser scanning and video and image-based $3 \mathrm{D}$ reconstruction system is enabling remote and virtual walk through on actual construction sites. These systems have the ability to minimize the travel times of supervisors and may increase the frequency of progress, quality and safety inspections by providing project supervisors with systems that are easily applicable (Golparvar-Fard et al. 2011, Jaselskis et al. 2011). The utilization of Building Information Modeling (BIM) by the project team would provide a more streamlined business process, associated project and site management methodologies including complete facilitation of construction knowledge during the full lifecycle of a building project (Arayici and Aouad 2010). Arayici et al. (2012) argued that BIM implementation serves as a useful alternative to addressing key construction sector issues, and offer solutions to these in order to increase productivity, efficiency, quality; reduce costs, lead times and duplications, via effective collaboration and communication of stakeholders in remote construction 
projects. These key findings, in terms of challenges, also lend support to the classification of the key challenges for construction project management in remote construction projects, such as human resources, cost, time, scope, and quality management; procurement and risk management, infrastructure and communication.

Justanyah and Sidawi (2011) and Sidawi 2010a,b, 2012a,b have studied the potentiality of Communications and Project Management Systems (CPMS) and whether it would help SEC in avoiding some construction problems, sorting out efficiently the site queries and improving the management of these projects. They pointed out that the CPMS would support SEC's management activities, particularly during the construction stages that witness long delays in providing feedback to the construction enquiries. CPMS can be used to provide fast feedback to the site personnel regarding the most problematic construction problems such as these related to the monitoring of the construction process, quality of work, procurement of materials and productivity levels.

The section above highlighted the problems and capabilities of ACMS regarding each of the project management aspects (see also Table 1). The previous research indicated that remote construction sites have unique problems that need unique and customized IT solutions. It also indicated that remote construction sites have some common problems such as these related to time, potential risk, pre-planning, cost, and logistic support despite that they are in different geographical locations.

\section{Barriers to the use of ACMS}

Despite fast developments in IT and the creation of many IT applications for the construction industry, some issues still hinder the applicability of these systems to construction project management. There is a problem with regard to the diffusion of IT in the construction industry and the absorption of IT into work practices. This includes the level of strategic IT investment by construction industry firms (Alshawi et al. 2009). Other barriers include IT technical shortages, deployment of the system on an ad hoc basis, isolated project management practices, and costly systems (Alshawi and Ingirige, 2003, Nuria, 2005, Leskinen, 2006, 2008). To minimize such barriers and enable ICT adoption, the following issues should be investigated (Margherita and Petti, 2010):

- Strategy: the action plan deriving from an integrated view of organization's goals and priorities, people expectations, and potential benefits;

Table 1 The management problems of remote construction projects and potential ACMS solutions

\section{Management problems \\ The extensive physical distance between project participants, sometimes extending over national boundaries, is the primary cause of delays in decision making (Deng et al., 2001) \\ Lack of project pre-planning, certainty, and/or clarity concerning project process integration (Kestle, 2009)}

These sites are often far from logistic support and suffer a continuous shortage of materials and specialized labor (Kestle and London, 2002, 2003). Contractors experience difficulty attracting and retaining skilled workers; and it is difficult to procure and access materials and equipment and site's conditions has a negative impact on productivity (McAnulty and Baroudi, 2010)

Misinterpretations and miscommunications of project results and needs issues; and a centralized decision-making process and lack of delegated authority to field personnel often hindered progress and communications (Kestle, 2009)

There is frequent shortage of materials, higher risk margins, serious delay in sorting out a number of project queries and Delays in decision-making and decisions are made autocratically, excessive costs, unfocused scope, and poor construction quality, unskilled workers, a lack of or no infrastructure (Justanyah and Sidawi, 2011 and Sidawi, 2010a, b, 2012a, b)

\section{Potential ACMS solutions}

ACMS can improve team members' ability to communicate and manage time and costs (Charoenngam et al., 2004)

ACMS use would reduce cost and save time, enhance communications and collaboration, improve productivity and partnership, and support the e-commerce and the customer (Nitithamyong and Skibniewski, 2004, 2006)

Construction costs can be reduced by $25 \%$ through efficient transfer of information by ACMS between the construction teams (Davidson and Moshini, 1990, Bowden, 2005)

ACMS use enables productivity enhancement of communication between project participants, reduction in project delays, alleviation of awareness of project issues among all parties, and easy access to and retrieval of project information (Alshawi and Ingirige 2003, and Stewart and Mohamed, 2004)

ACMS use minimizes delays due to the arrival of updated drawings and documents, reduces visits to sites and traveling time to meetings, reduces time and money spent on disputes, automates repetitive routine processes, and eliminates paper reports (Alshawi and Ingirige 2003, and Stewart and Mohamed, 2004)

ASMC have the ability to minimize the travel times of supervisors and may increase the frequency of progress, quality and safety inspections by providing project supervisors with systems that are easily applicable (Golparvar-Fard et al., 2011, Jaselskis et al. 2011).

ACMS would help SEC's supervisors to monitor the Procurement, supply and consumption of construction materials. It would would help SEC eliminating some causes of potential delays. It helps in monitoring closely and frequently the contractors/ sub-contractors and site personnel activities and construction process, performance and outcomes (Justanyah and Sidawi 2011 and Sidawi 2010a, b, 2012a, b) 
- People: the single individuals' attitude and the overall organizational context which impact on the level of willingness and readiness to change;

- Process: the real unit of analysis and trigger of change in terms of alternative redesign scenarios and associated impact; and

- Enablers: the potential facilitators of implementation at technological and organizational level

Nitithamyong and Skibniewski (2007) investigated the impact of project success/ failure factors on performance of WPMS. This is regarding the following aspects: project characteristics, project team characteristics, service provider characteristics and system characteristics. In respect to the project and project team characteristics, they found that strategic, time, cost, quality, Risk, and communication improvement are significantly linked: owner type, project type, project cost, project duration, and starting stage of PM-ASP development. In regards to project team characteristics, the above project factors are significantly linked with the project Parties deciding for the use of PM-ASP.

Anumba et al. (2006) found that the following structural and social impediments to the integration of ICT system: commitment from top management, continuing support for users, highly reliable systems, involvement of users, easy to use systems, effective project management, clear cost justification, well proven systems, full training, precisely defined objectives, facilities to meet specific needs, use of pilots or prototypes and organizational change (see also Grimshaw and Kemp 1989).

\section{Methods}

The literature review have highlighted the potentials of the ACMS in a number of geographical locations around the world so it would be useful to test the useful of these systems for large companies within the context of KSA. This study examines the management of remote construction sites by large companies and how the use of ACMS would help these companies improving its' management of remote projects. The objectives of the research are:

- To find out possible management and

communications problems of remote construction sites; - To explore how these problems would be sorted out using ACMS and how ACMS would help in improving management practices; and

- To identify possible barriers to the full application of ACMS

To achieve the research objectives, it is argued that a combination of quantitative (i.e. a questionnaire) and qualitative (i.e. interviews) research tools are used. This combination was chosen because it would enable the researchers in creating and studying the visual representation of data. Also, the findings that relate to each method will be used to complement one another and, at the end of the study, to enhance theoretical or substantive completeness (Ausubel 1968). The research tools i.e. the questionnaire and interviews, were designed in accordance to the literature review, the findings of the pilot study that carried out in 2009 and the previous research on remote construction sites that has been conducted in the KSA in 2010.

The targeted population consists of contractors and companies' supervisors/engineers of Aramco (Saudi Arabian Oil Company), Royal commission of Jubail (RCJ) (petrochemical company), SABIC (Saudi Basic Industries Corporation and it a petrochemicals manufacturer), compendium of construction and consultancy companies which are working on remote sites of University of Dammam. These companies are located or have branches in the Eastern province, KSA and they have a number of remote construction sites of different sizes. This targeting method would provide feedback from the two major project's parties i.e. the owner and the contractor, which would increase the applicability of the proposed solutions regarding management and tools to both of them.

In mid-2012, phone calls were made to the managers and contractors of above mentioned companies asking them whether they would be happy to participate in the field survey. Seventy questionnaire forms were sent out to individuals who expressed their willingness to take part in the field survey. The progress of filling up the questionnaire forms was checked up by phone. These forms were filled in and returned back. However, after examining the returned forms, it was found that 23 of these are invalid as many parts have not been completed. Eventually, the total number of valid questionnaires is 47 . The face to face interviews were conducted in January 2013 and these were with one consultant that represents the University of Dammam in respect of supervision of a number of construction projects for the university's, two engineers who represent a contracting company which is working on one of the University's projects, and seven engineers of various specialists i.e. architectural, structural engineering, and HVAC, who are working in the private projects department of the Royal Commission of Jubail. The total number of interviewees was ten. The researchers were not able to conduct any interview with Aramco engineers and contractors as none was willing to participate in the interviews stage.

The analysis of the results was undertaken using SPSS16 for quantitative analysis and a number of data visualization techniques were used. Mean, standard deviation, and skewness values were calculated, and the researchers inspected links between potential factors (i.e. independent variables) and dependent variables. 
Cross-referencing (i.e. similarities and non similarities) technique was used to analyze the qualitative data. This technique enabled the researchers to classify the data into categories and make comparisons, and allowed rational interpretation and judgment. The following sections discuss remote construction site challenges and the potentials and barriers to the application of ACMS.

\section{Results and discussion}

\section{Remote construction projects problems}

On a daily basis, the most requested information by the construction team on the remote construction site from the regional supervision office include the followings: clarification of design information, reporting QA/QC problems, contract drawings, initiation site inspections, reporting the site inspection outcomes, as-built records, and delay records. There is however, substantial delay in dealing with the following site's queries: revisions to submittals, meeting minutes, updated Schedule, clarification of Design information, as-built records, contract drawings and reporting QA/QC problems (Figure 1). Respondents said that there is a strong negative impact of the delay in providing feedback for the following remote project's queries on the project's process and performance: clarification of design information, contract drawings, updated Schedule, contract specifications, reporting QA/QC problems, and budget, and as-built records. Respondents were asked about remote construction sites' problems.

They said that the most frequent problems of these sites are: delay in project time table, unavailability of supervision engineers on the remote project site due to their heavy workload, the company's tendering system that obligate the choice of the lowest bidding value, the shortage of skilled labour on the site, and delay in the approval of contractor's submissions by the supervision engineers (Figure 2).

The ANOVA results showed significant links between the delay in providing information and the remote construction site problems. It showed that the more delay in providing information on the budget is associated with higher occurrence of the following problematic issues on the site: mistakes in construction works, shortage in site equipment, delay in the conduction of field survey by the contractor, unavailability of the supervision engineers during sample testing stages, improper construction methods implemented by the contractor and inadequate equipment used. The more delay in providing the products catalogue is associated with higher occurrence of ineffective planning and scheduling of the project by the contractor (Table 2). The more delay in providing the visitors $\log$ is associated with more delay in project time table. The more delay in providing revisions to submittals information is associated with higher occurrence of the use of inadequate equipment. The more delay in initiating site inspections is associated with more delay in project time table. The more delay in reporting QA problems are associated with more delay in project time table.

The interviews revealed the following facts:

- Very few Saudi nationals are working on construction projects in KSA and there is a problem of employing non Saudis who are in KSA or recruiting HR from aboard because of the high recruitment fees on foreign contracts; - The remoteness of remote projects has an impact of on social life of workers. The higher rank staff would

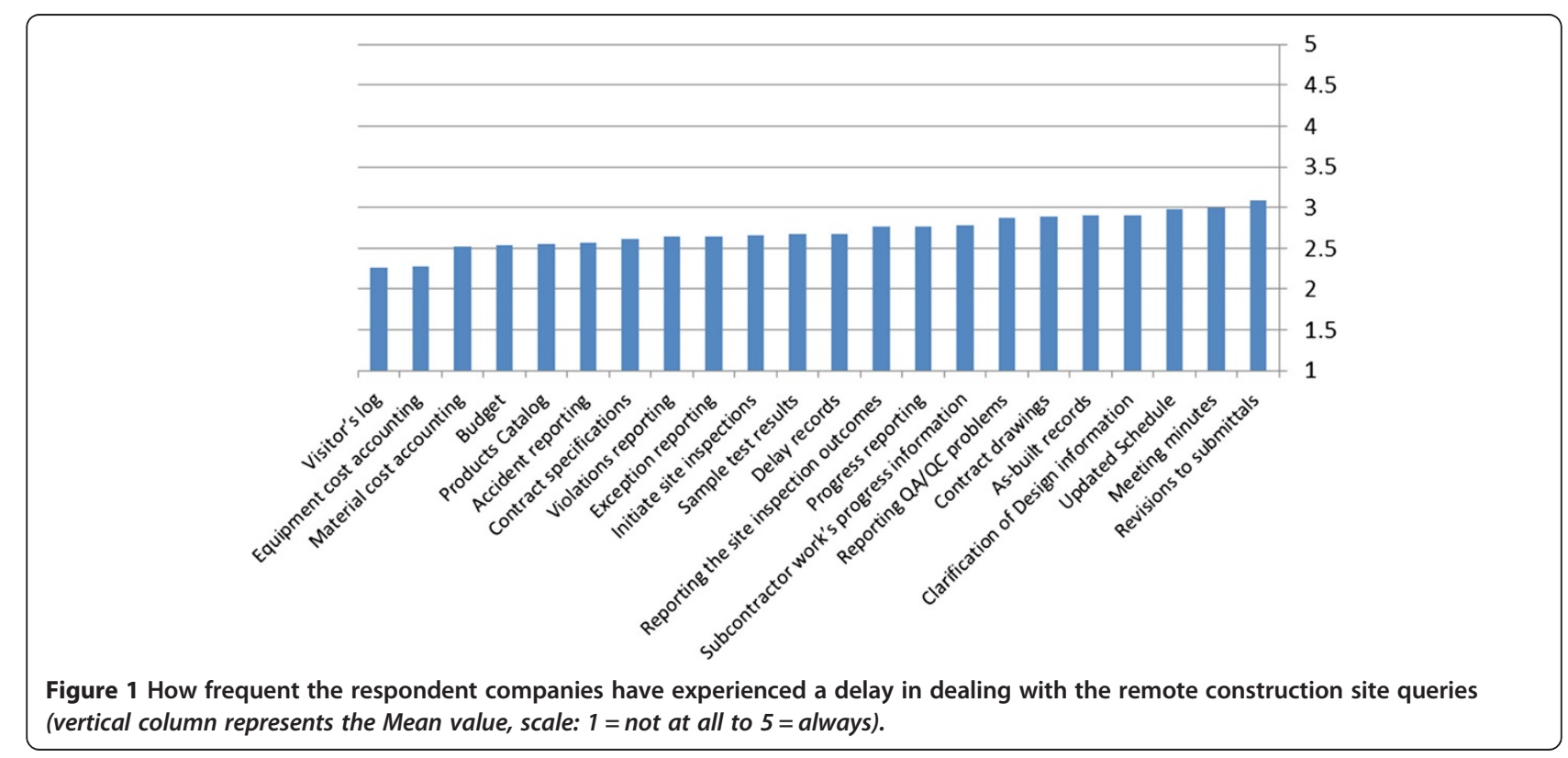




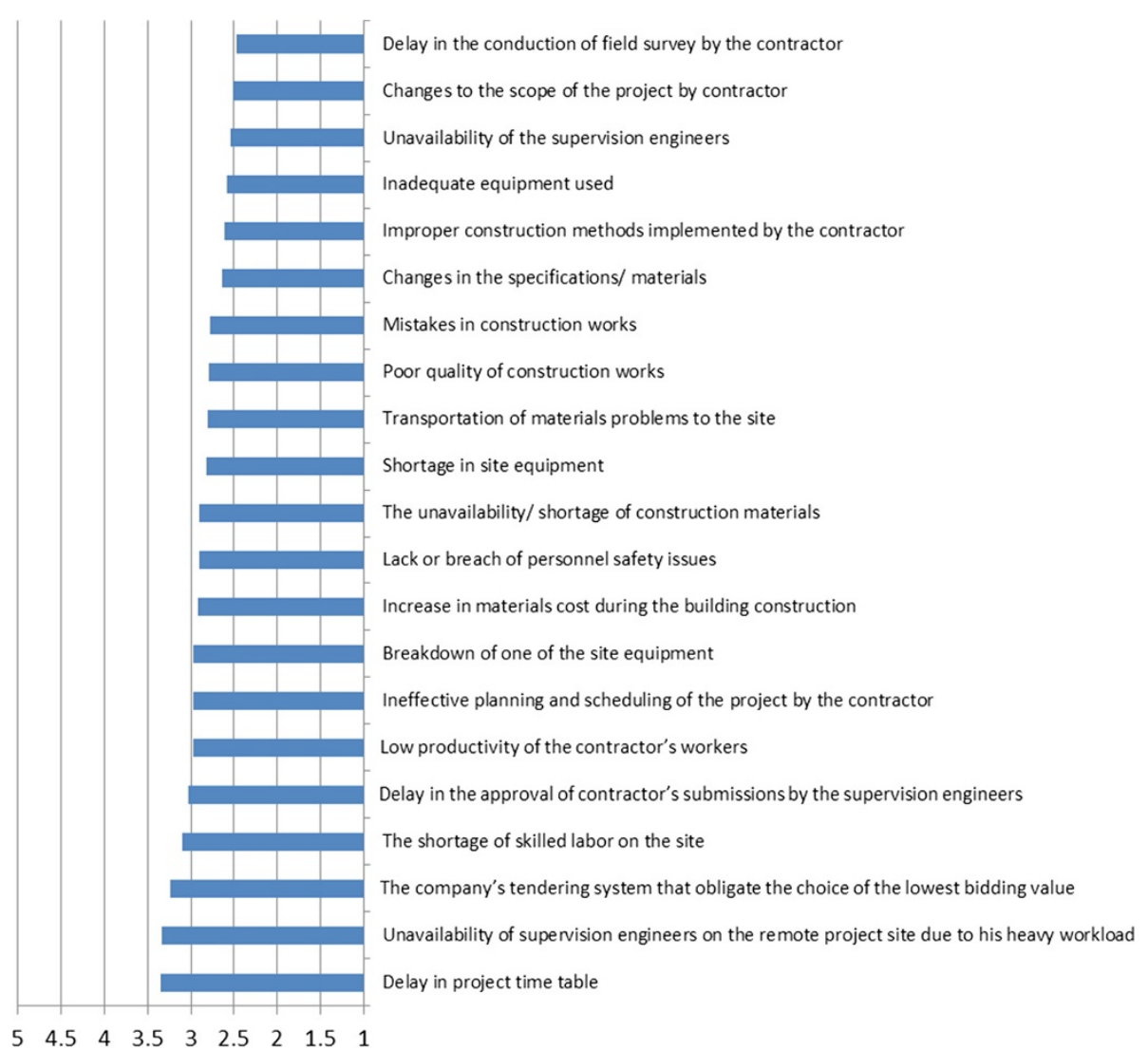

Figure 2 How frequent the following issues happen during the remote construction project's period (i.e. from start to completion). (horizontal column represents the Mean value, scale: $1=$ does not happen at all to $5=$ always happens).

find working in a remote project very difficult as they will be away from their families and the social life. The absence of electronic social communications would affect negatively the workers' productivity who are away from their families;

- Limited authority is given to the site managers and this sometimes causes substantial delay;

- Due to the cultural differences, social conflicts between workers take place and in one case, these are not reported to the project's owner or to the authorities. Also, one should be careful and choose his words when talking with staff from different backgrounds as some would understand certain words as an abuse or a threat;

- It is noticed that there are differences in productivity between workers from different backgrounds so this should be considered as it would delay the work in some parts of the project;

- all interviewed staff have QA measures but they do not apply sustainability measures;

- in one company, the contractor has weak commitment to providing frequent progress report to the supervision office as this has not been specified in the contract;
- risk management and materials' procurement is programmed. However, each remote project has its' merits, estimation of insurance on labour, equipment, third party, risk level etc. and unexpected issues such as absence of road net or bad roads status or so. Differences in estimating the risk level exist between the contractor, the owner and other concerned parties. This affects how the project would be run by each party and may create conflict of interests between these parties;

- the government bidding and tendering system for design or/and construction of a project takes into account the lowest bidding price regardless of the quality which affect the quality of projects;

- materials were originally specified according to the specification but sometimes the materials that brought to the site did not comply with the specifications; - one of the main causes of construction problems is the conflict between design documents that are produced by different specialists;

- the contractor should thoroughly survey the site. He should check the utilities i.e. sewage, electricity, water on the site or if there anything that would affect the project's kick-off such as the availability of road 
Table 2 ANOVA results showing correlation between the factor; delay experienced in dealing with the budget query with a number of dependent variables namely; the frequency of problematic issues during the remote construction project's period, (level of significance $<0.05$ )

\begin{tabular}{|c|c|c|c|c|c|c|}
\hline \multicolumn{2}{|l|}{$\begin{array}{l}\text { Dependent variable: the frequency of problematic issues during the remote } \\
\text { construction project's period (i.e. from start to completion }\end{array}$} & \multicolumn{5}{|c|}{$\begin{array}{l}\text { Independent variable (factor): the delay experienced } \\
\text { in dealing with the budget query }\end{array}$} \\
\hline & & \multirow{2}{*}{$\begin{array}{l}\text { Sum of Squares } \\
6.105\end{array}$} & \multirow{2}{*}{$\begin{array}{l}\text { df } \\
4\end{array}$} & \multirow{2}{*}{$\begin{array}{l}\text { Mean Square } \\
1.526\end{array}$} & \multirow{2}{*}{$\frac{\mathbf{F}}{2.758}$} & \multirow{2}{*}{$\begin{array}{l}\text { Sig. } \\
0.043\end{array}$} \\
\hline Mistakes in construction works & Between Groups & & & & & \\
\hline & Within Groups & 18.818 & 34 & 0.553 & & \\
\hline \multirow[t]{2}{*}{ Shortage in site equipment } & Between Groups & 15.838 & 4 & 3.959 & 3.934 & 0.01 \\
\hline & Within Groups & 33.215 & 33 & 1.007 & & \\
\hline \multirow[t]{2}{*}{ Delay in the conduction of field survey by the contractor } & Between Groups & 15.123 & 4 & 3.781 & 5.469 & 0.002 \\
\hline & Within Groups & 22.121 & 32 & 0.691 & & \\
\hline \multirow[t]{2}{*}{ Unavailability of the supervision engineers during sample testing stages } & Between Groups & 19.735 & 4 & 4.934 & 5.869 & 0.001 \\
\hline & Within Groups & 27.739 & 33 & 0.841 & & \\
\hline \multirow[t]{2}{*}{ Improper construction methods implemented by the contractor } & Between Groups & 5.554 & 4 & 1.388 & 3.325 & 0.022 \\
\hline & Within Groups & 13.365 & 32 & 0.418 & & \\
\hline \multirow[t]{2}{*}{ Inadequate equipment used } & Between Groups & 10.849 & 4 & 2.712 & 4.082 & 0.008 \\
\hline & Within Groups & 22.587 & 34 & 0.664 & & \\
\hline
\end{tabular}

networks. SEC - for instance- did not update information of some sites so when these sites are possessed by RCJ, they may find electric cables, foundations, SEC temporary station, and septic tanks under the ground;

- changes would happen to the original design scheme.

In one occasion, the granite panels for the facades were replaced with precast concrete panels to speed up the construction, and in another incident, solar panels were included in the original design scheme, but later on these were abandoned, and the project was connected to the national electric grid. The reason was that the owner of the project was scared of trying something for the first time and considered it of high risk. In another incident, the desalination station was designed with a certain capacity. Later on, it was discovered that the capacity is not enough and should be extended to cover the present and future needs; and

- some contractors do not have the background to manage certain types of projects and remote projects. They are incapable to manage their financial affairs, materials' procurement and how to provide qualified human resources.

\section{The present and potential use of the ACMS}

The systems and tools that are mostly used by respondents for management of the projects and communications between the remote construction site and the supervision office are: e-mail through internet/intranet/ wireless/satellite, mobile phone, laptop, site visit, weekly or monthly reports and weekly meetings. Advanced computer tools such as Web-based Project Management system (WPMS), personal digital assistants, virtual private network, and construction Robots are of little use.
Respondents said that the use of the following systems would help in efficiently manage the remote construction projects: e-mail through internet/intranet/wireless/Satellite, intelligent mobile phones, tablet computer, and Web-based Project Management System. On the other hand, they considered the following systems would help less in managing remote sites: the Walkie-talkie, web monitoring cameras and construction robots. Respondents said the ACMS would highly accelerate the feedback of the following site queries: reporting QA/QC problems, contract drawings, reporting the site inspection outcomes, clarification of design information, accident reporting and violations reporting. On the other hand, it was considered of lesser help in providing fast feedback regarding the following sites queries: material cost accounting, equipment cost accounting, and visitor's log (Table 3).

Respondents said that ACMS would be very helpful in achieving the following project lean and sustainable values: pursuing perfection by continuous improvement, specifying precisely value from the perspective of the ultimate customer/owner, identifying clearly the process that delivers what the customer/owner values (the value stream) and eliminating construction works' waste.

On the other hand, it would provide less support to managers who aim to achieve the following values: protecting the KSA people health and reducing the use of natural resources. The interviewees said that ACMS would help:

- Facilitating the procurement of materials whereas requests for materials are sent electronically to the head office for approval. However, as some materials are imported from aboard, there is a need to see the material or a sample before purchasing it. 
Table 3 How fast the ACMS would accelerate the feedback of the remote construction site' queries, (Mean value scale: $\mathbf{1}=$ do not accelerate to $\mathbf{5}=$ highly accelerate)

\begin{tabular}{lccc}
\hline $\begin{array}{l}\text { Type of the remote construction } \\
\text { site's query }\end{array}$ & Mean & $\begin{array}{c}\text { Std. } \\
\text { deviation }\end{array}$ & Skewness \\
\hline Reporting QA/QC problems & 4.13 & 0.992 & -0.825 \\
Contract drawings & 4.11 & 0.841 & -0.468 \\
Reporting the site inspection outcomes & 4.06 & 0.942 & -0.62 \\
Clarification of Design information & 4.02 & 0.944 & -1.016 \\
Accident reporting & 3.96 & 1.083 & -0.879 \\
Violations reporting & 3.94 & 1.131 & -1.001 \\
Progress reporting & 3.91 & 1.08 & -1.014 \\
Revisions to submittals & 3.89 & 0.983 & -0.209 \\
Initiate site inspections & 3.89 & 1.005 & -0.45 \\
Contract specifications & 3.83 & 1.018 & -0.693 \\
Updated Schedule & 3.83 & 1.253 & -0.72 \\
Sample test results & 3.77 & 1.165 & -0.812 \\
Exception reporting & 3.74 & 1.206 & -0.879 \\
Meeting minutes & 3.68 & 1.163 & -0.72 \\
As-built records & 3.64 & 1.293 & -0.73 \\
Delay records & 3.63 & 1.388 & -0.752 \\
Subcontractor work's progress & 3.48 & 1.11 & -0.452 \\
information & & & -0.368 \\
Products Catalog & 3.36 & 1.342 & -0.242 \\
Budget & 3.33 & 1.266 & -0.447 \\
Material cost accounting & 3.26 & 1.307 & -0.316 \\
Equipment cost accounting & 3.2 & 1.222 & -0.135 \\
Visitor's log & 3.13 & 1.377 & \\
\hline & & & \\
\hline
\end{tabular}

- sending requests for specialist HR to recruitment agents who recruit HR from overseas. It also helps in mobilization of HR from a project to another as needed. - overcoming cultural differences and understanding the other and, for instance, including religious festivals holidays in the project schedule

- providing fast social communications between the worker on site and his family at home or abroad is essential and this would bring relief to the worker. Fast communications channels are required.

- delegating certain level of authority to the sites' managers. This would help in mobilization of HR and equipment between sites; and

- providing updated benchmarks/standards/measures on the net so staff would refer to it, while examining certain case. Thus they would take the decision without getting an approval from the higher authorities

However, the management system should be transparent, so any investment opportunity by the headquarters should be known by all concerned departments.

\section{Barriers to the use of ACMS}

This study suggests that the above mentioned companies experience a number of unique construction management performance problems. The study found significant links between these performance issues and how far the ACMS would help in providing fast feedback to the site's queries and in achieving project's values. Therefore, these issues would affect the adoption and utilization of the ACMS; and would be considered as barriers to the use of ACMS (see also Nitithamyong and Skibniewski 2007).

The field survey show frequent construction problems and delays in responding to some site queries (see also Deng et al. 2001). Also it showed some unexpected problems i.e. infrastructure, social, psychological as mentioned above (see McAnulty and Baroudi 2010). This would raise the risk level and by turn the cost of remote projects in comparison with normal projects. The interviews show problems related to materials' procurement, transportation and installation, differences in estimating the risk level between project parties (Kestle and London 2002, 2003).

Differences in estimating cost, time, scope, and quality management between parties and the traditional management practices can be seen as obstacles to ACMS full utilization. There is lack of skilled human Resources, and there are cultural differences and a language barrier between workers and communication problems between the senior staff and labor. The cultural differences occasionally create tensions between teams (ibid).

ACMS systems are of little use by the respondents and site personnel (i.e. the contractor, sub-contractor or the owner's employees). The ACMS was considered of little help regarding the financial matters such as Budget, material cost accounting, and equipment cost accounting. Also, the ACMS would provide lesser support to managers who aim to achieve the following values: protecting Saudi Arabia's peoples' health and reducing the use of natural resources. The interviews indicated that in some companies, fragmented and standalone software was used for managing projects. The IT system of the project owner at the company headquarters is sometimes not connected with its departments and mostly not linked with the contractor or other project parties' systems. Also, problems regarding the weak IT infrastructure (e.g. slow servers) are experienced. Staff finds some difficulty in dealing with updated developments of software. In one of the companies, IT staff have good IT skills but without good construction background. None of the interviewees use Building Information Modelling (BIM) programs or receives BIM documents from consultants or design firms. All documents received are AutoCAD ones or based on AutoCAD drawings.

\section{Conclusions: How to maximize the potentials}

To maximize the potentials of ACMS, it should be designed to provide innovative and intelligent solutions to the unique 
remote construction problems. The recommendations for the application of ACMS below can be generalized to other remote construction sites aboard taking into account the location and project's parameters. The design of future ACMS should consider the following issues:

A. The management side: The present researchers that design of ACMS would have the following

management levels:

I. Strategic planning level: the company's strategy should be programmed into the ACMS system and this includes the strategic management of all its' remote projects in terms of how to coordinate activities, mobilization/demobilization of HR, equipment, materials, transportation, and other logistics issues.

II. Project planning and process: automated design and pre-planning of site activities is essential as this should consider the risky variables' of the environment, the remote site and project as mentioned above. There are differences in risk estimation between project parties, and this should be discussed during the design stage and the level of risk should be agreed by all parties thus embedded in the system and all contract documents.

The ACMS should provide flexible decision-making mechanisms and consider short and long-term partnering, and sharing information and management and communications tools with contractors and other project parties. This would enhance knowledge integration and help to foster innovative ideas that dramatically improve projects (Barlow 2000). During the construction stage, ACMS should provide precise daily control and follow-up procedures regarding issues such as remote examination of work quality, monitoring productivity of site workers, and calculation of material consumption rates. Some problems seem to be generated during the early stages of the project. These should be programmed as well. ACMS should enable the creation of new hypothesized cases, and the input of existing cases of emergency scenarios and the generation of possible intelligent solutions. ACMS would have an educational/training part that helps various project parties to learn about unique previous problems of the construction of remote projects and possible solutions. This would help staff overcoming present remote site's problems. The system would also have an assessment section wherein it checks whether the contractor has the ability and knowledge to run the designated remote project. ACMS should provide transparency and it should consider how to reduce the negative impacts of the project on the environment and environmental parameters on project performance and processes.

It is important to provide all the necessary information i.e. benchmarks/standards/measures on the system so it would be used by staff without the need to get the approval from the higher authority. However, financial, sustainable, and environmental aspects of the project should be considered in the design of the ACMS system.

III.Human resources level: the future ACMS would help all parties to respond efficiently to unexpected issues, to quickly sort queries, to lead multinational teams, to sort out potential social conflicts and find out possible solutions, to coordinate with other remote sites' managers and overcome communications problems. Religious festivals and holidays should be considered and frequent social events should be programmed. The system should give the managers the required level of authority and this helps in mobilization and demobilization of $\mathrm{HR}$ and equipment between distant projects.

Staff should be informed about the benefits and advantages of new ACMS systems. Managers should be trained on site and how to manage remote sites virtually. The design of the new ACMS in-house or adoption of new ACMS should be discussed with the contractors and supervisors/engineers to find out their views, perceptions and expectations.

B. the social and cultural side: ACMS should help bridging cultural differences and overcoming language barriers between workers and communication problems between the senior staff and labor.

ACMS should help facilitating the procurement of materials whereas requests for materials are sent electronically to the headquarters for approval. ACMS should help in sending requests for specialist HR to recruitment agents who recruit HR from overseas. Through this system, fast social communications should be provided between the worker on site and his family at home or abroad.

Competing interests

The authors declare that they have no competing interests.

\section{Authors' contributions}

BS and AA together carried out the filed study. Subsequently, the gathered data was analyzed. All authors contributed to the writing of the manuscript. Both authors read and approved the final manuscript.

Received: 8 January 2014 Accepted: 11 April 2014

Published: 30 April 2014 


\section{References}

Ahuja, V, Yang, J, \& Shankar, R. (2010). IT-enhanced communication protocols for building project management. Engineering, Construction and Architectural Management Journal, 17(2), 159-179.

Ahuja, V, Yang, J, \& Shankar, R. (2009). Benefits of collaborative ICT adoption for building project management. Construction Innovation: Information, Process, Management, 9(3), 323-340.

Alshawi, M, \& Ingirige, B. (2003). Web-enabled project management: an emerging paradigm in construction. Automation in Construction, 12, 349-364.

Alshawi, M, Goulding, J, Khosrowshahi, F, Lou, E, \& Underwood, J. (2009). How strategic is IT investment in the construction industry? A UK Perspective, Modern Built Environment -Knowledge Transfer Networks, Intelligent Buildings Index (pp. 1-3).

Anumba, CEH, Dainty, A, Ison, S, \& Sergeant, A. (2006). Understanding structural and cultural impediments to ICT system integration: A GIS-based case study. Engineering Construction and Architectural Management, 13(6), 616-633.

Arayici, Y, \& Aouad, G. (2010). Building information modelling (BIM) for construction lifecycle management, in: Construction and Building: Design, Materials, and Techniques (pp. 99-118). NY, USA: Nova Science Publishers.

Arayici, Y, Egbu, C, \& Coates, P. (2012). Building information modelling (BIM) implementation and remote construction projects: Issues, Challenges and Critiques, ITcon Vol. 17, Special Issue Management of remote construction sites and the role of IT Systems (pp. 75-92). http://www.itcon.org/2012/5. Accessed 10 July 2013.

Ausubel, DP. (1968). Educational Psychology: A Cognitive View. New York, NY: Holt, Rinehart \& Winston

Barlow, J. (2000). Innovation and learning in complex construction projects. Research Policy, 29, 973-989.

Becerik, B. (2005). Critical Enhancements for Improving Adoption of OPM Technologies. Harvard Graduate School of Design, Barrie Award Winning Reports, PMI Educational Foundation Funded. http://i-lab.usc.edu/ documents/Enhancements\%20for\%20IT\%20Adoption_PMI_Sept\%202005.pdf. Accessed 10 December 2012.

Bowden, S. (2005). Application of mobile IT in construction (PhD Dissertation): University of Loughborough, Department of Civil \& Building Engineering.

Charoenngam, C, Ogunlana, SO, Ning-Fu, K, \& Dey, PK. (2004). Re-engineering construction communication in distance management framework. Business process management Journal, 10(6), 645-672.

Davidson, CH, \& Moshini, R. (1990). Effects of organisational variables upon task organisations' performance in the building industry. Building Economics and Construction Management, 4, 17-22.

Deng, ZM, Li, H, Tam, CM, Shen, QP, \& Love, PED. (2001). An application of the Internet-based project management system. Automation in Construction, 10(Elsevier), 239-246.

Golparvar-Fard, M, Peña-Mora, F, \& Savarese, S. (2011). Integrated sequential as-built and as-planned representation - with D4AR - 4 dimensional augmented reality - tools in support of decision-enabling tasks in the AEC/FM industry. ASCE Journal of Construction Engineering and Management. http://dx.doi.org/10.1061/ (ASCE)CO.1943-7862.0000371. Accessed 10 April 2012.

Grimshaw, DJ, \& Kemp, B. (1989). Office automation in local government in the UK. Local Government Studies, 15(2), 7-15.

Jaselskis, E, Ruwanpura, J, Becker, T, Silva, L, Jewell, P, \& Floyd, E. (2011). Innovation in Construction Engineering Education Using Two Applications of Internet-Based Information Technology to Provide Real-Time Project Observations. ASCE Journal of Construction Engineering and Management. http://dx.doi.org/10.1061/ (ASCE)CO.1943-7862.0000297. Accessed 12 July 2012.

Justanyah, N, \& Sidawi, B. (2011). The dilemma of communications and management of remote construction projects in the kingdom of Saudi Arabia, Sixth International Conference on Construction in the 21st Century (CITC-VI) (pp. 395-406). Kuala Lumpur, Malaysia: Construction Challenges in the New Decade. ISBN 1-884342-02-5.

Kestle, L, \& London, K. (2002). Towards the development of a conceptual design management model for remote sites. In C Formoso \& G Ballard (Eds.), 10th Annual Conference on 'Lean Construction (IGLC-10) (Vol. 1, pp. 309-322). Gramado: Federal University of Rio Grande Do Sul.

Kestle, L, \& London, K. (2003). Remote site design management -the application of case study methodology. In Paper presented at the Postgraduate construction research conference. Melbourne: RMIT.

Kestle, L. (2009). Remote Site Design Management (PhD thesis). NZ: University of Canterbury.

Leskinen, S. (2006). Mobile Solutions and the Construction Industry Is it a working combination? VTT publications. http://www.vtt.fi/inf/pdf/publications/2006/ P617.pdf. Accessed 18 February 2011
Leskinen, S. (2008). Mobile technology in the Finnish construction industry - present problems and future challenges. 21st Bled eConference eCollaboration: Overcoming Boundaries through Multi-Channel Interaction June 15-18, 2008. Slovenia: Bled.

Margherita, A, \& Petti, C. (2010). ICT-enabled and process-based change: an integrative roadmap. Business Process Management Journal, 16(3), 473-491.

McAnulty, S, \& Baroudi, B. (2010). Construction Challenges in Remote Australian Locations. Leeds, United Kingdom: Association of Researchers in Construction Management (ARCOM) Conference.

Nitithamyong, P, \& Skibniewski, MJ. (2004). Web-based construction project management systems: how to make them successful? Automation in Construction, 13, 491-506.

Nitithamyong, P, \& Skibniewski, JM. (2006). Success/Failure factors and performance measures of web-based construction project management systems: professionals' viewpoint. Journal of Construction Engineering and Management ASCE, 132(1), 80-87.

Nitithamyong, P, \& Skibniewski, MJ. (2007). Key success/failure factors and their impacts on system performance of web-based project management systems in construction ITcon Vol. 12 (pp. 39-59). http://www.itcon.org/2007/3. Accessed 14 January 2011.

Nuria, FM. (2005). Life cycle document management system for construction. PhD thesis. Universitat Politechica De Catalunya. http://www.tdx.cat/bitstream/ handle/10803/6160/01 Nfm01 de12.pdf?sequence=1. Accessed 12 October 2011.

Pena-mora, F, Vadhavkar, S, \& Aziz, Z. (2009). Technology strategies for globally dispersed construction teams. Journal of Information Technology in Construction. http://www.itcon.org/2009/08. Accessed 5 August 2011.

Sidawi, B. (2010a). The sustainable management of remote construction projects. Fes, Morocco: Arab Society of Computer Aided Architectural Design AsCAAD. ISBN 978-1-907349-02-7.

Sidawi, B. (2010b). The use of advanced electronic management systems to manage remote projects in the Kingdom of Saudi Arabia (pp. 633-642). Leeds, UK: Association of researchers in Construction management conference (ARCOM). ISBN 978-0-9552390-4-5.

Sidawi, B. (2012a). Remote construction projects' problems and solutions: the case of SEC. ASC 48th International Conference held in conjunction with the CIB Workgroup 89. UK: Birmingham City University.

Sidawi, B. (2012b). Potential use of communications and project management systems in remote construction projects: the case of Saudi Electric Company. Journal of Engineering, Project, and Production Management, 2(1), ISSN 2221-6529 (Print), ISSN 2223-8379 (Online), 14-22, 2012.

Stewart, RA, \& Mohamed, S. (2004). Evaluating web-based project information management in construction: capturing the long-term value creation process. Journal of Automation in Construction, Elsevier Science, 13(4), 469-479.

Thomas, S, Palaneeswaran, E, \& Kumaraswamy, MM. (2003). Web-based centralized multiclient cooperative contractor registration system Journal of Computing in Civil Engineering, 17(1), 28-37.

Thorpe, D. (2000). E-projects in action - the online remote construction management research project (CIIA Fifth Annual Conference: Innovation in Construction). Australia: Construction Industry Institute.

Vadhavkar, S, \& Pena-Mora, F. (2002). Empirical Studies of the Team Interaction Space: Designing and Managing the Environments for Globally Dispersed Teams (International Workshop on the Role of Empirical Studies in Understanding and Supporting Engineering Design Work). Gaithersburg, MD: USA: NIST.

Wamelink, JWF, Stoffelem, M, \& der Aalst, V. (2002). W.M.P. International Council for Research and Innovation in Building and Construction. CIB w78 conference, Aarhus School of Architecture, 12-14 June 2002. Denmark: CIB.

Yang, J, Ahuja, V, \& Shankar, R. (2007). Managing Building Projects through Enhanced Communication - An ICT Based Strategy for Small and Medium Enterprises, CIB World Building Congress 2007 (pp. 2334-2356). South Africa: CIB.

Zou, P, \& Roslan, B. (2005). Different perspectives towards using web-based project management systems in construction: large enterprises versus small- and medium-sized enterprises. Architectural Engineering and Design Management, $1(2), 127-143$.

doi:10.1186/2213-7459-2-3

Cite this article as: Sidawi and Alsudairi: The potentials of and barriers to the utilization of advanced computer systems in remote construction projects: case of the Kingdom of Saudi Arabia. Visualization in Engineering 2014 2:3 